\title{
IMPLEMENTASI METODE ARTIFICIAL NEURAL NETWORK DALAM MEMPREDIKSI HASII UJIAN KOMPETENSI KEBIDANAN (STUDI KASUS: AKADEMI KEBIDANAN DEHASEN BENGKULU)
}

\author{
Arius Satoni Kurniawansyah \\ Teknik Informatika, Fakultas Ilmu Komputer, Universitas Dehasen Bengkulu \\ Jl. Meranti Raya No.32 Sawah Lebar. Kode Pos 38228 \\ ariussatoni@yahoo.co.id
}

\begin{abstract}
Abstrak: Berdasarkan Peraturan Bersama antara Kementerian Pendidikandan Kementrian Kesehatan Tentang Ujian Kompetensi Tahun 2013 No. 36/2013 \& No.I/Iv/Pb/2013, maka seluruh Perguruan Tinggi Kesehatan di Seluruh Indonesia wajib untuk melaksanakan Ujian Kompetensi sebagai syarat utama mendapatkan gelar bagi mahasiswa kesehatan dalam menyelesaikan studinya.Di Akademi Kebidanan Dehasen Bengkulu, Lulus Ujian Kompetensi juga merupakan syarat utama untuk meraih gelar Amd.Keb. Oleh karena itu mahasiswa Kebidanan Dehasen Bengkulu wajib mengikuti Ujian Kompetensi. Sebelum melakukan Ujian Kompetensi, dosen ataupun pihak kampus tentu ingin mengetahui prediksi jumlah kelulusan dari mahasiswa yang akan melaksanakan Ujian Kompetensi. Adapun teknik dalam memprediksi hasil kelulusan ini menggunakan Algoritma Backpropagation. Penelitian ini dilakukan dengan mengamati beberapa variabel penelitian yang sering dipertimbangkan oleh perguruan tinggi kebidanan khususnya bagian akademik dalam memprediksi hasil ujian kompetensi, yaitu 7 variabel nilai dalam ujian kompetensi kebidanan yaitu nilai dengan tipe soal tentang Ibu Hamil, Ibu Bersalin, Ibu Nifas, BBL, KB, Kespro, dan Patologi. Variabel nilai tersebut digunakan sebagai variabel input pada algoritma Backpropagation serta keputusan Lulus dan Gagal sebagai outputnya. Hasil penelitian ini adalah berupa sebuah knowledge dalam memprediksi hasil ujian kompetensi kebidanaan dengan mengimplementasikan algoritma Backpropagation pada perangkat lunak Matlab R2010a. Dari hasil penerapan algoritma Backpropagation, didapatkan tingkat akurasi $90 \%$ dalam menentukan hasil yang lebih akurat sesuai dengan data aktual untuk sebuah acuan prediksi hasil kelulusan ujian kompetensi kebidanan di Akademi Kebidanan Dehasen Bengkulu.

Kata Kunci : Backpropagation, Prediksi.
\end{abstract}

Abstract: Based on the Joint Regulation between the Ministry of Education and Ministry of Health on Competency Examination Year 2013 No. 36/2013 \& No.I / Iv / Pb / 2013, then all Health Universities throughout Indonesia are required to conduct the Competency Exam as the main requirement to obtain a degree for health students in completing their studies. In Dehasen Bengkulu Midwifery Academy, Competency Exam Pass is also the main requirement for the title of Amd.Keb. Therefore Dehasen Bengkulu Midwifery students must follow the Competency Exam. Before conducting a Competency Examination, lecturers or campus would want to know the prediction of the number of graduation from students who will carry out the Competency Exam. The technique in predicting the results of this graduation using Backpropagation Algorithm. This study was conducted by observing some research variables that are often considered by midwifery colleges, especially the academic in predicting the results of the competency exam, namely 7 variables in the obstetric competency test value with the type of questions about Pregnant Women, Maternal Woman, Nifas, BBL, KB , Kespro, and Pathology. Value variables are used as input variables on the Backpropagation algorithm as well as decisions Passed and Failed as output. The result of this research is in the form of a knowledge in predicting the result of kebidanaan competency test by implementing Backpropagation algorithm on Matlab R2010a software. From the results of the application of 
Backpropagation algorithm, obtained $90 \%$ accuracy rate in determining more accurate results in accordance with actual data for a prediction reference of the passing of midwifery competency examination in Dehasen Bengkulu Midwifery Academy.

Keywords: Backpropagation, Prediction.

\section{PENDAHULUAN}

Berdasarkan Peraturan Bersama antara Kementerian Dikbud \& Kementrian Kesehatan Tentang Ujian Kompetensi Tahun 2013 No. 36/2013 \& No.I/Iv/Pb/2013, maka seluruh Perguruan Tinggi Kesehatan di Seluruh Indonesia wajib untuk melaksanakan Ujian Kompetensi sebagai syarat utama mendapatkan gelar bagi mahasiswa kesehatan dalam menyelesaikan studinya.

Di Akademi Kebidanan Dehasen Bengkulu, Lulus Ujian Kompetensi juga merupakan syarat utama untuk meraih gelar Amd.Keb. Oleh karena itu mahasiswa Kebidanan Dehasen Bengkulu wajib mengikuti Ujian Kompetensi. Sebelum melakukan Ujian Kompetensi, dosen ataupun pihak kampus tentu ingin mengetahui prediksi nilai dari Mahasiswa yang akan melaksanakan Ujian Kompetensi.

Referensi [1] menunjukkan bahwa Jaringan syaraf tiruan dianggap sebagai salah satu matematika-komputasi yang modern metode yang digunakan untuk memecahkan masalah yang dinamis dan diantisipasi maju perilaku sistem selama periode waktu. Dengan belajar untuk mengenali pola dari data yang lain. Metode komputasi dan statistik gagal menyelesaikannya, jaringan saraf tiruan mampu memecahkan masalah.

Referensi [2] menunjukkan bahwa Menggunakan Algoritma jaringan saraf untuk diagnosis anemia untuk anak di bawah usia 18 tahun, disajikan. Itu jaringan dilatih dengan menggunakan data dari hasil uji hemogram dari 30 pasien dan dokter ahli. Jaringan memiliki 5 input (HGB, HCT, MCV, MCH, MCHC) dan output. Simulasi pada 20 pasien yang berbeda menunjukkan bahwa Jaringan Syaraf Tiruan mendeteksi penyakit dengan akurasi yang tinggi. Dalam tulisan ini, terlihat bahwa anemia diagnosis dapat dilakukan melalui metode jaringan saraf.

Referensi [3] menunjukkan bahwa Rough Set adalah pendekatan untuk mengekstrak pengetahuan dan hubungan antara data dan nilainilai data dalam beberapa tahun terakhir. Referensi [4] menunjukkan bahwa Toleransi Rough Set Model bersantai persyaratan transitivitas hubungan kesetaraan, dan sering digunakan dalam pencarian informasi untuk menemukan kelompok istilah indeks dalam basis data teks besar. Referensi [5] menunjukkan bahwa Untuk melatih umpan-maju ANN classifier, kembali propagasi diaplikasikan sesuai dengan Duda dkk, dan 3Sistem lapisan terpilih sebagai ANN BP standar. Lapisan input dari jaringan memiliki enam neuron yang sesuai untuk enam nilai fitur input.

Jaringan Saraf Tiruan (JST) atau Artificial Neural Network merupakan suatu pendekatan yang berbeda dari metode AI lainnya. JST merupakan suatu model kecerdasan yang diilhami dari struktur otak manusia dan kemudian diimplementasikan menggunakan program computer yang mampu menyelesaikan sejumlah proses perhitungan selama proses pembelajaran berlangsung. Algoritma Artificial Neural Network (ANN) merupakan model penalaran yang didasarkan pada otak manusia. ANN terdiri dari sejumlah prosesor sangat sederhana dan saling berhubungan yang disebut neuron. Neuron yang terhubung dengan pembobotan (weight) melewatisinyal dari neuron satu ke neuron yang lain. 
Dengan adanya algoritma Artificial Neural Network maka pihak kampus dapat memprediksi nilai mahasiswa yang akan melaksanakan Ujian Kompetensi dari data nilai mahasiswa tahun sebelumnya.

\section{LANDASAN TEORI}

\section{A. Knowledge Discovery in Database (KDD)}

Referensi [6] menunjukkan bahwa KDD merupakan proses mengekstrak pola atau model dari data dengan menggunakan suatu algoritma yang spesifik. Adapun proses KDD sebagai berikut:

\section{Data Selection:}

Data operasional perlu dilakukan sebelum tahap penggalian informasi dalam KDD dimulai.

\section{Preprocessing: Data Mining}

Dapat dilaksanakan, perlu dilakukan proses cleaning duplikasi data, memeriksa data yang inkonsisten, dan memperbaiki kesalahan pada data, seperti kesalahan cetak (tipografi). Juga dilakukan enrichment data yang sudah ada dengan data atau informasilain yang relevan dandi perlukan untuk KDD, seperti data atau informasi eksternal.

\section{Transformation: coding}

Yang telah dipilih, sehingga data tersebut sesuai Data Mining coding KDD merupakan proses kreatif dan sangat tergantung pada jenis atau pola informasi yang akandicari dalam database.

\section{Data Mining:}

Informasi menarik dalam data terpilih dengan menggunakan teknik atau metode tertentu.

\section{Interpretation / Evaluation :}

Data Mining ditampilkan dalam bentuk yang mudah dimengerti oleh pihak yang berkepentingan. Tahap ini merupakan bagian dari proses KDD interpretation mencakup pemeriksaan apakah pola atau informasi yang ditemukan bertentangan dengan fakta atau hipotesa yang ada sebelumnya atau tidak. Tahapan proses KDD dapat dilihat pada Gambar 1

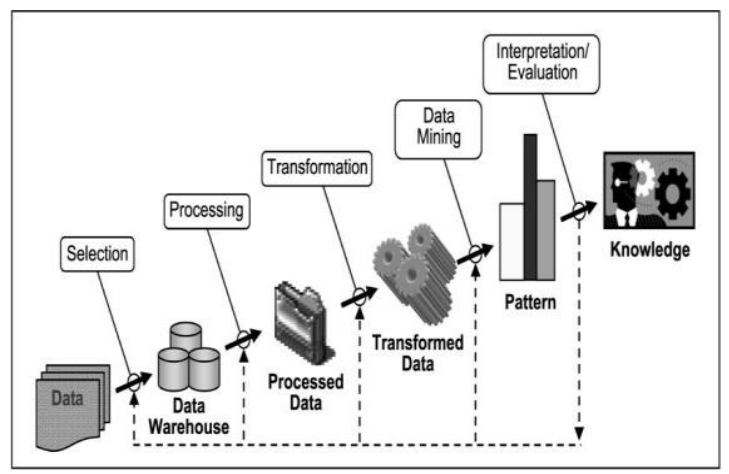

Gambar 1. Tahapan dalam KDD

\section{B. Data Mining}

Data Mining adalah proses untuk mendapatkan informasi dengan melakukan pencarian pola dan relasi-relasi yang tersembunyi di dalam timbunan data yang banyak. Referensi [7] menunjukkan bahwa Data Mining atau sering disebut sebagai knowledge discovery in database (KDD) adalah kegiatan yang meliputi pengumpulan, pemakaian data historis untuk menemukan keteraturan, pola atau hubungan dalam data berukuran besar. Keluaran Data Mining ini bisa dipakai untuk membantu pengambilan keputusan di masa depan. Pengembangan KDD ini menyebabkan penggunaan pattern recognition semakin berkurang karena telah menjadi bagian Data Mining.

\section{Algoritma Backpropagation}

Algoritma pelatihan dengan metode backpropagation dimunculkan pada tahun 1969. Neural network dengan metode backpropagation ini memiliki tahap pengenalan terhadap jaringan multi layer, yaitu:

1. Nilai di kirim melalui input layer ke hidden layer (forward) sampai ke output layer (actual output) 
2. Actual output dibandingkan dengan output yang diharapkan jika ada perbedaan maka dinyatakan sebagai error.

3. Selanjutnya eror di kirim secara backward mulai dari output layer ke hidden layer kemudian diteruskan ke input layer.

\section{METODOLOGI PENELITIAN}

\section{A. Pendahuluan}

Dalam melakukan penelitian agar hasilnya bisa maksimal, tentunya harus mengikuti kaidah-kaidah (metode) yang telah ditetapkan. Metode penelitian yang akan diterapkan adalah metode penelitian ilmiah yang telah diajarkan di bangku perkuliahan sarjana. Metodologi penelitian ini memuat tentang kerangka kerja penelitian yang akan dibahas di bawah ini.

Pada bab ini akan dibahas metodologi penelitian untuk mengidentifikasi data mining, analisa data dan pada akhirnya mencari kesimpulan di dalam memprediksi hasil Ujian Kompetensi mahasiswa Akademi Kebidanan Dehasen Bengkulu.

\section{B. Kerangka Kerja}

Dalam metodologi penelitian ada urutan kerangka kerja yang harus diikuti, urutan kerangka kerja ini merupakan gambaran dari langkahlangkah yang harus dilalui agar penelitian ini bisa berjalan dengan baik. Kerangka kerja yang harus diikuti bisa dilihat pada Gambar 2.

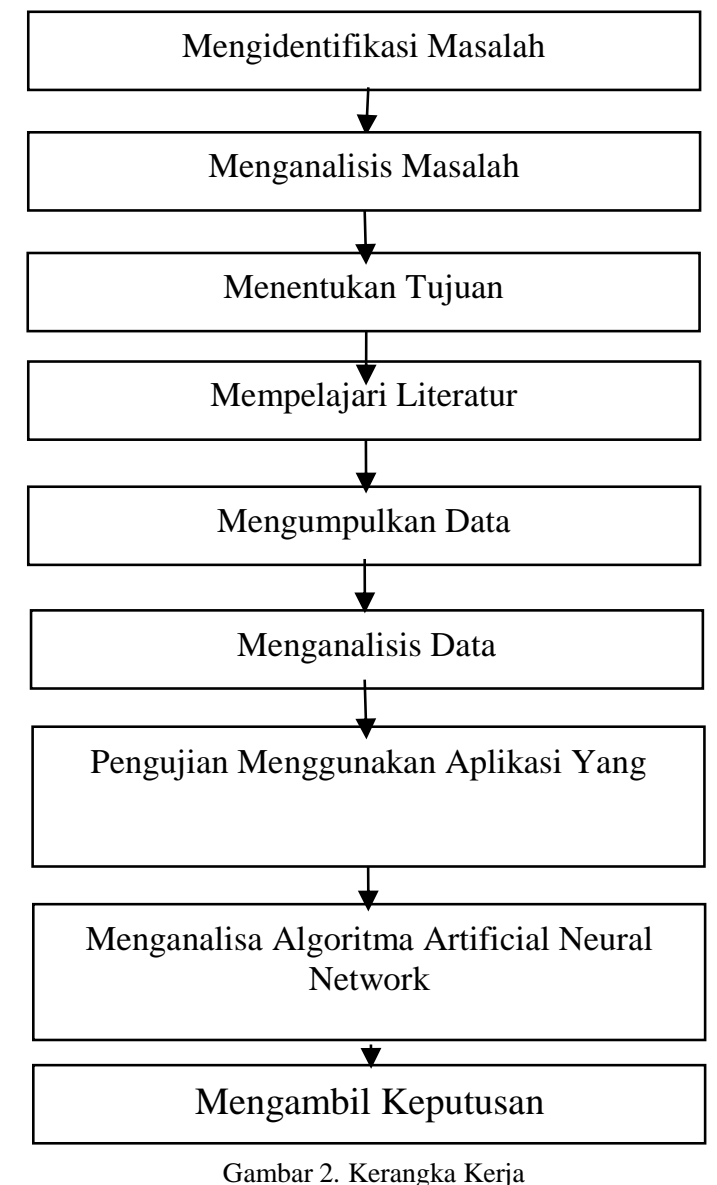

\section{ANALISIS DAN PERANCANGAN}

\section{A. Analisa Data}

Dalam memprediksi hasil ujian kompetensi kebidanan Akbid Dehasen Bengkulu menggunakan metode Artificial Neural Network. Penulis menentukan beberapa variabel yang menjadi kriteria kelulusan mahasiswa. Data yang diambil adalah data hasil Ujian Kompetensi Kebidanan Akbid Dehasen Bengkulu tahun 2014 dan 2015 .

Data hasil ujian kompetensi kebidanan akan diolah dengan menggunakan Algoritma Backpropagation. Jumlah input layer pada algoritma backpropagation sebanyak 7 variabel input yaitu, Nilai tipe soal tentang Ibu Hamil, Ibu Bersalin, Ibu Nifas, BBL (Bayi baru lahir), KB (Keluarga Berencana), Kespro (Kesehatan 
Reproduksi), dan Patologi. Adapun output layernya adalah lulus atau gagal.

\section{B. Pemilihan Variabel}

Data sampel yang diuji dalam penelitian ini adalah 200 mahasiswa yang mengikuti ujian kompetensi di Akademi Kebidanan Dehasen Bengkulu Tahun 2014 dan 2015. Adapun format data sebagai berikut:

1. Nama Mahasiswa

2. Nilai tipe soal tentang Ibu Hamil

3. Nilai tipe soal Ibu Bersalin

4. Nilai tipe soal Ibu Nifas

5. Nilai tipe soal BBL (bayi baru lahir)

6. Nilai tipe soal KB (Keluarga Berencana)

7. Nilai tipe soal Kespro (Kesehatan Reproduksi)

8. Nilai tipe soal Patologi

Adapun yang diambil sebagai variabel masukan atau input adalah nilai tipe soal tentang Ibu Hamil, Ibu Bersalin, Ibu Nifas, BBL (Bayi baru lahir), KB (Keluarga Berencana), Kespro (Kesehatan Reproduksi), dan Patologi dalam penerapan Algoritma Backpropagation dan Rough Set untuk memprediksi nilai hasil ujian kompetensi kebidanan.

Algoritma pelatihan pada backpropagation sebagai berikut:

\section{Initiliazation}

Memberikan nilai awal terhadap nilai-nilai yang diperlukan oleh neural network seperti weight, threshold.

\section{Activation}

Nilai-nilai yang diberikan pada tahap initiliazation akan digunakan pada tahap activation.Dengan melakukan perhitungan:

a. Menentukan actual output pada hidden layer

b. Menghitung actual output pada output layer

3. Weight Training
Pada tahap weight training dilakukan 2 (dua) kegiatan yaitu:

a. Menghitung error gradient pada output layer

b. Menghitung error gradient pada hidden layer

\section{Iteration}

Pada tahap ini dilakukan proses pengulangan sampai mendapat error yang minimal. (Badrul Anwar, 2011).

Dalam menentukan hasil Ujian Kompetensi Kebidanan yang dilakukan pada setiap tahunnya dipengaruhi oleh beberapa faktor utama, yaitu faktor nilai tipe soal tentang Ibu Hamil, Ibu Bersalin, Ibu Nifas, BBL (Bayi baru lahir), KB (Keluarga Berencana), Kespro (Kesehatan Reproduksi), dan Patologi. Hal ini disebabkan karena selama ini data hasil ujian kompetensi kebidanan Akbid Dehasen Bengkulu yang berupa data nilai mahasiswa tidak dianalisis dan diolah untuk dijadikan sebagai bahan dalam memprediksi nilai hasil ujian kompetensi kebidanan pada tahun berikutnya. Padahal yang terkandung di dalam data hasil ujian kompetensi Kebidanan Akbid Dehasen Bengkulu terdapat sebuah pengetahuan yang baru untuk sebuah prediksi Institusi Akbid Dehasen Bengkulu dalam melaksanakan kegiatan Ujian Kompetensi.

Jaringan Syaraf Tiruan dengan Algoritma Backpropagation pada prediksi hasil Ujian Kompetensi menggunakan 7 buah variabel input, yaitu :

$\mathrm{x}_{1}=$ Nilai tipe soal tentang Ibu Hamil (IH)

$\mathrm{x}_{2}=$ Nilai tipe soal Ibu Bersalin (IB)

$\mathrm{X}_{3}=$ Nilai tipe soal Ibu Nifas (IN)

$\mathrm{x}_{4}=$ Nilai tipe soal Bayi Baru Lahir (BBL)

$\mathrm{X}_{5}=$ Nilai tipe soal Keluarga Berencana $(\mathrm{KB})$

$\mathrm{x}_{6}=$ Nilai tipe soal Kesehatan Reproduksi (Kespro)

$\mathrm{x}_{7}=$ Nilai tipe soal Patologi $(\mathrm{Pt})$ 


\section{Pemodelan JST untuk Prediksi Hasil Ujian}

\section{Kompetensi Kebidanan}

Prosedur pemodelan Jaringan Syaraf Tiruan untuk memprediksi hasil ujian Kompetensi Kebidanan di Akademi Kebidanan Dehasen Bengkulu terdiri dari beberapa langkah, yaitu : Penyiapan data, pemilihan arsitektur, pembelajaran (learning, training), pengujian (testing). Untuk menilai kedekatan atau kecocokan data hasil pengamatan, dilakukan uji kecocokan dengan menggunakan fungsi objektif atau fungsi kesalahan yang merupakan persamaan dari perhitungan dan pengamatan.

1. Variabel Masukan

Agar data dapat dikenali oleh jaringan dan sekaligus dapat diproses menggunakan perangkat lunak (software) maka data harus diubah kedalam bentuk numerik. Di dalam penelitian ini variabel masukan dalam memprediksi hasil Ujian Kompetensi Kebidanan adalah nilai tipe soal tentang Ibu Hamil, Ibu Bersalin, Ibu Nifas, BBL (Bayi baru lahir), KB (Keluarga Berencana), Kespro (Kesehatan Reproduksi), dan Patologi.

\section{Data Input dan target}

Ada beberapa hal yang harus didefinisikan dalam menerapkan Jaringan Syaraf Tiruan untuk memprediksi hasil Ujian Kompetensi Kebidanan, yaitu: Nilai input yang akan dimasukkan pada sistem dalam bentuk angka-angka yang telah di inisialisasikan dalam sistem. Sistem akan melakukan pengolahan data apakah output akan sama dengan yang diharapkan atau tidak. Sebagai output adalah hasil Ujian Kompetensi yaitu lulus atau gagal.

\section{IMPLEMENTASI DAN PENGUJIAN}

\section{A. Pendahuluan}

$\mathrm{Bab}$ ini akan membahas proses implementasi dan pengujian metode Artificial Neural Network dengan menggunakan aplikasi Matlab R2010a. Pada tahap pengujian ini akan dideskripsikan teknik menggunakan tools Matlab R2010a dan diselaraskan dengan membuktikan dari analisa metode terhadap permasalahan yang ada untuk memprediksi hasil Ujian Kompetensi Kebidanan di Akademi Kebidanan Dehasen Bengkulu.

\section{B. Implementasi Metode Artificial Neural}

Network

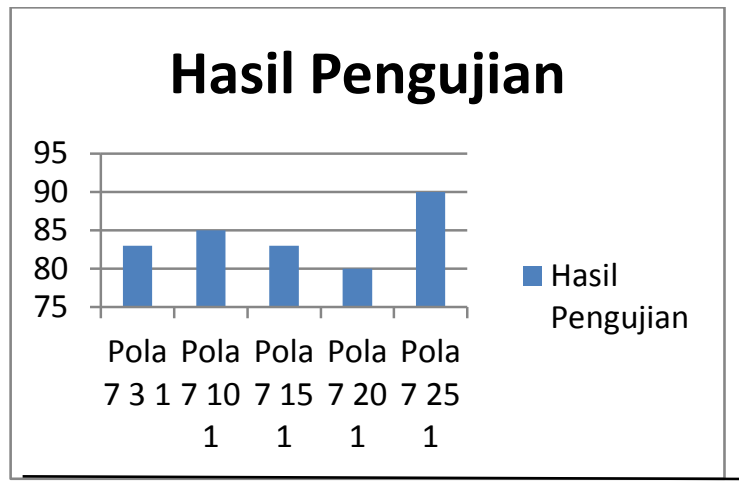

Gambar 3. Grafik Tingkat Akurasi Hasil Pengujian Dengan 5 Arsitektur

Dari Gambar 3. Dapat dilihat bahwa yang paling tepat untuk memprediksi hasil ujian kompetensikebidanan adalah pola arsitektur 7-251yaitu dengan tingkat akurasi $90 \%$.

Adapun gambar hasil pengujian pada perangkat lunak Matlab R2010a dengan pola arsitektur 725-1: 


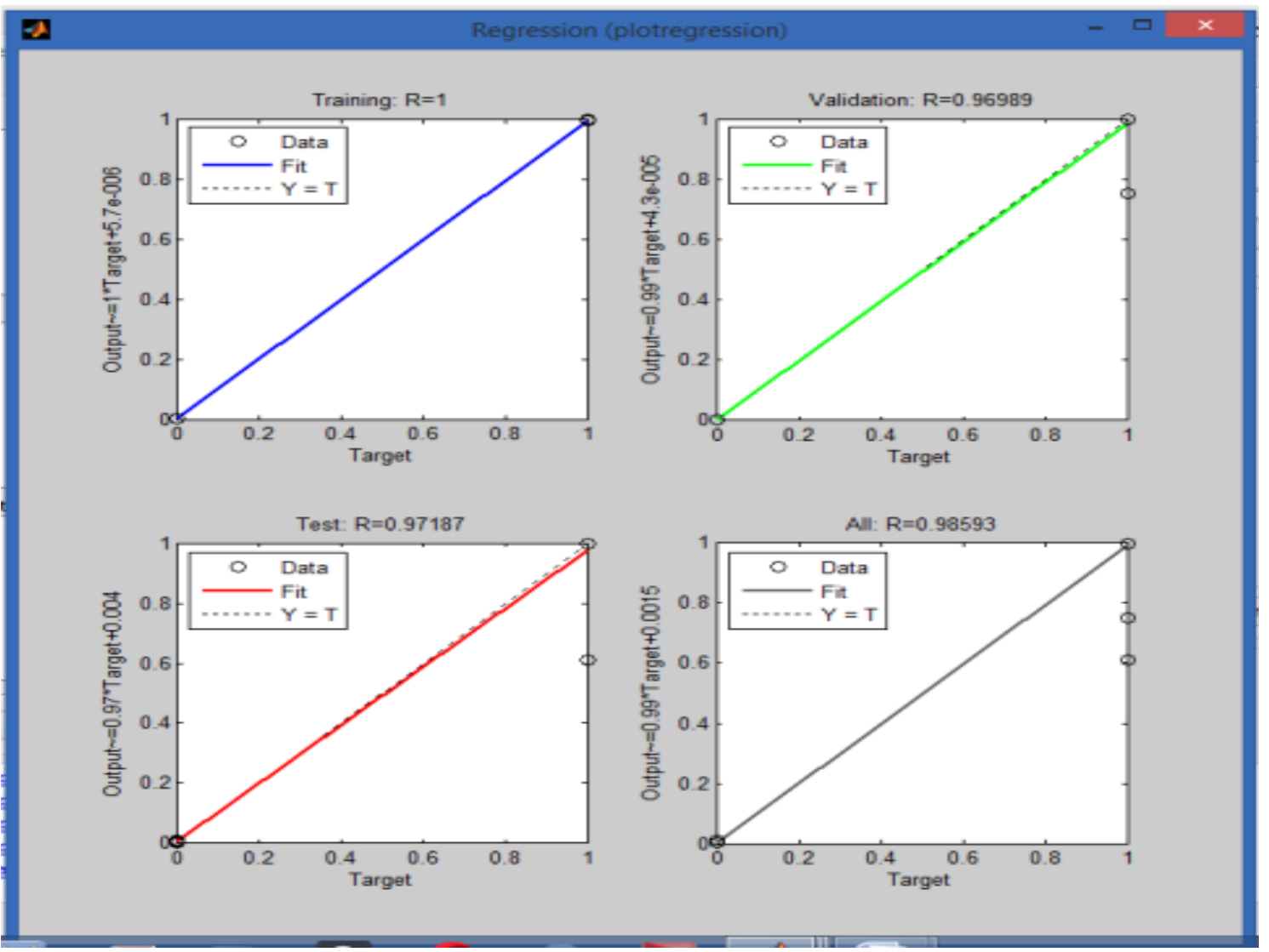

Gambar 4. Hasil Pengujian Pola Arsitektur 7-25-1

\section{PENUTUP}

\section{Kesimpulan}

Dari uraian pada bab 1 sampai dengan bab 5 yang sudah dibahas sebelumnya dapat ditarik kesimpulan:

Metode Artificial Neural Network dengan menerapkan algoritma backpropagation dalam memprediksi hasil ujian kompetensi kebidanan menggunakan data input dan data output dari data hasil ujian kompetensi tahun sebelumnya. Dalam Jaringan Syaraf Tiruan melalui program aplikasi Matlab R2010a, telah berhasil melakukan serangkaian tahapan yang diperlukan dan dapat memprediksi hasil ujian kompetensi kebidanan Akbid Dehasen Bengkulu untuk tahun yang akan datang. Dari hasil prediksi menggunakan perangkat Matlab R2010a tersebut menghasilkan tingkat keakurasian dalam memprediksi hasil ujian kompetensi pada beberapa pola yaitu pola arsitektur 7-3-1, 7-10-1, 7-15-1, 7-20-1, dan 7-25-

1. Dari beberapa pola tersebut pola arsitektur 7-251 dianggap lebih akurat dengan tingkat akurasi 90\% untuk memprediksi hasil ujian kompetensi kebidanan di Akademi Kebidanan Dehasen Bengkulu pada ujian kompetensi kebidanan yang akan datang.

\section{Saran}

Salah satu tujuan penelitian ini adalah agar teknik dalam memprediksi hasil ujian kompetensi kebidanan di Akademi Kebidanan Dehasen Bengkulu dapat diimplementasikan atau diterapkan dengan baik, untuk itu saran yang dapat diperhatikan untuk pengimplementasian dari teknik ini adalah: 
1. Pada penelitian ini, penulis mencoba sebuah teknik dalam memprediksi yaitu dengan menerapkan algoritma backpropagation, didapatkan tingkat akurasi $90 \%$ dalam menentukan hasil yang lebih akurat sesuai dengan data aktual untuk sebuah acuan prediksi hasil kelulusan ujian kompetensi kebidanan di Akademi Kebidanan Dehasen Bengkulu. Oleh sebab itu perlu dilakukan penerapan metode yang lebih baik lagi dalam memprediksi hasil ujian kompetensi kebidanan di Akbid Dehasen Bengkulu untuk yang akan datang.

2. Untuk mendapatkan hasil prediksi yang baik sangat diperlukan data/knowledge yang lebih banyak dan lebih lengkap untuk mendukung dalam prediksi.

\section{REFERENSI}

[1] Seyyed Reza Khaze, et al (2013). "Application of Artificial Neural Networks In Estimating Participation In Elections". IJITMC. Vol. 1, No. 3. 23

[2] Kaya, et al. (2014). Diagnosis Of Anemia In Children Via Artivicial Neural Network. IJISAE. Vol. 4, No. 2.24

[3] Tripathy, et al. (2011). A Framework For Intelligent Medical Diagnosis Using Rough Set With Formal Concept Analysis. IJAIA. Vol. 2, No. 2. 45-46.

[4] Duntsch, et al. (2015). Rought Set Clustering. Technical Report\# CS-15-02. 1.

[5] Nukala, et al. (2014). An Efficient And Robust Fall Detection System Using Wireless Gait Analysis Sensor With Artificial Neural Network (ANN) And Support Vector Machine (SVM) Algorithms. 3. 31.

[6] Mabrur dan Lubis. (2012). Penerapan Data Mining untuk Memprediksi Kriteria Nasabah Kredit. KOMPUTA. Vol. 1. No. 1. 5-6.

[7] Fadlina, (2014). Data Mining untuk Analisa Tingkat Kejahatan Jalanan dengan Algoritma Association Rule Metode Apriori. INTI. Vol. 3. No. 1. 145. 